\title{
Germline Mutations in BRCA1 and BRCA2 in Polish Families Predisposed to Breast and Ovary Cancers
}

E. Grzybowska ${ }^{1}$, A. Jasinska ${ }^{5}$, P. Kozlowski ${ }^{5}$, H. Zientek ${ }^{1}$,

W. Krzyzosiak ${ }^{5}$, B. Utracka-Hutka ${ }^{2}$,

J. Wloch ${ }^{3}$ and

J. Rogozinska-Szczepka ${ }^{4}$

${ }^{1}$ Department of Tumor Biology, Center of Oncology, Maria Sklodowska-Curie

Memorial Institute, Gliwice, Poland

${ }^{2}$ Chemotherapy Clinic, Center of Oncology,

Maria Sklodowska-Curie Memorial Institute, Gliwice, Poland

${ }^{3}$ Surgery Clinic, Center of Oncology, Maria

Sklodowska-Curie Memorial Institute,

Gliwice, Poland

${ }^{4}$ Radiotherapy Clinic, Center of Oncology, Maria Sklodowska-Curie Memorial Institute, Gliwice, Poland
${ }^{5}$ Cancer Genetics Group, Institute of Bioorganic Chemistry, Poznan, Poland

Germline mutations in BRCA1 and BRCA2 were analyzed in DNA isolated from white blood cells of patients with a family history of breast and ovarian cancers. We found one mutation in the BRCA1 gene - 300T/G missense mutation in exon 5 disrupting the zinc finger - already found in other families. In 5 families three different mutations were discovered in BRCA2. All these mutations are new and have not been described earlier. A frameshift mutation 9630delC causing truncation of the BRCA2 protein was identified in three different families which indicates a founder effect. Two other mutations were 9599A/T missense and 6886del5 frameshift, truncating the BRCA2 protein. 


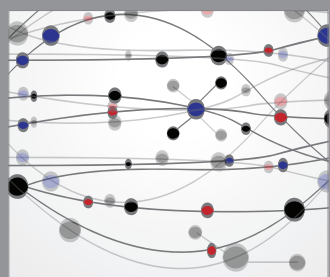

The Scientific World Journal
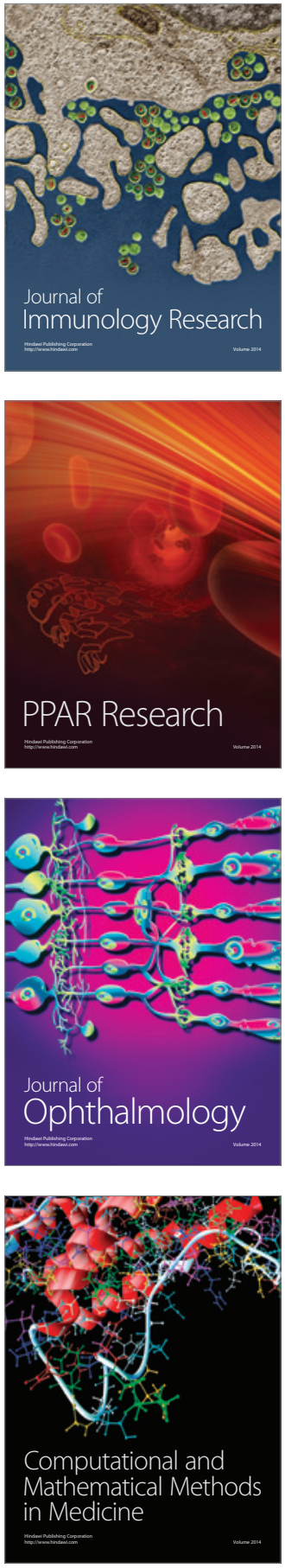

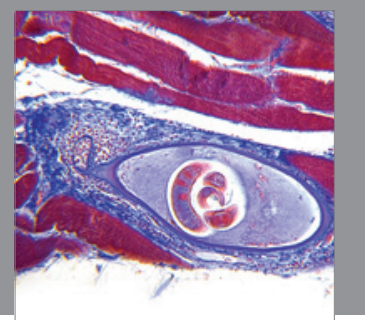

Gastroenterology

Research and Practice
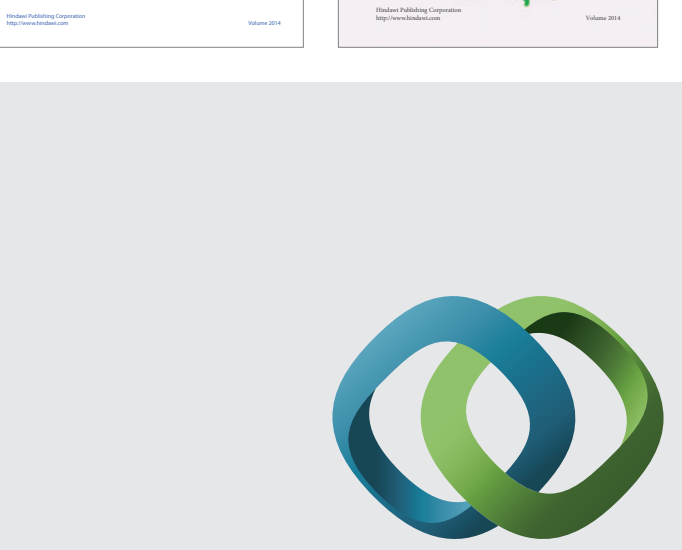

\section{Hindawi}

Submit your manuscripts at

http://www.hindawi.com
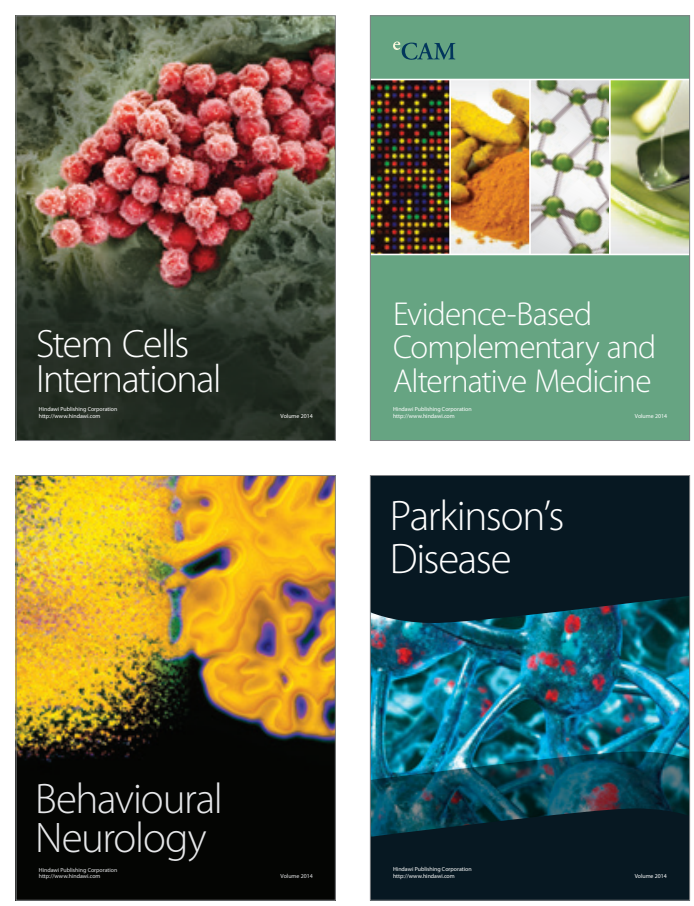

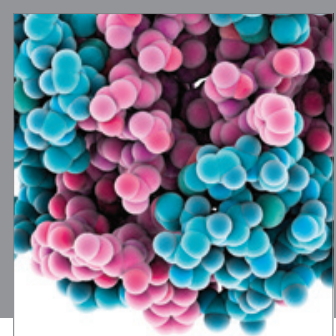

Journal of
Diabetes Research

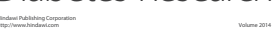

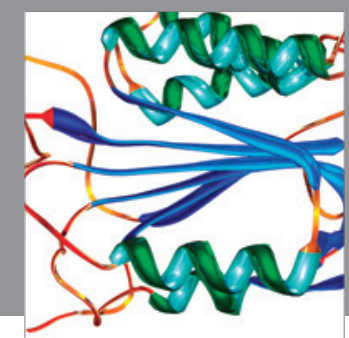

Disease Markers
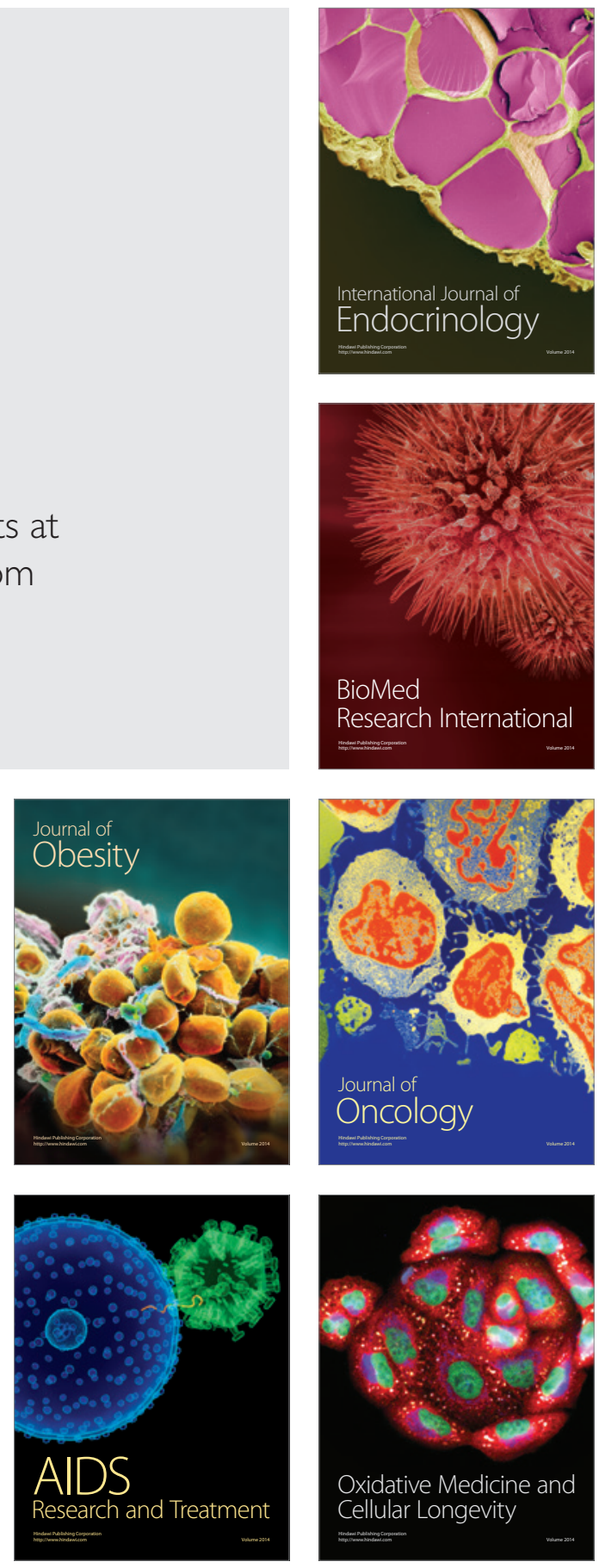